\title{
Modeling optimal solutions with the use of heat technologies based on graph theory
}

\author{
Natalya Trukhina ${ }^{1}$, and Ella Okolelova ${ }^{1, *}$ \\ ${ }^{1}$ Voronezh State Technical University, 394006, 84, 20-let Oktyabrya str., Voronezh, Russia
}

\begin{abstract}
The article describes the types of energy efficient technologies focused on energy saving. The presented technologies have significantly improved performance, while the disadvantage is high cost, which is the main factor preventing the introduction of energy saving technologies in construction. In this regard, solve the problem of optimizing the choice of the possible heat saving technologies of construction enterprises based on their financial and production capabilities based on graph theory. As a result, identify the technology yielding the greatest effect at minimum cost. The decision process is formalized as a graphical structure. In this case, the problem of finding the optimal solutions solved in graph theory. Graphical modeling of the structure of relations allows to visualize and organize variants of the consistent use of energy-saving technologies construction companies. On the basis of the construction of adjacency matrices organization of construction production is planned based on the use of energy-saving technologies determines the best combination of the ability of the construction company and the effectiveness to the execution of the technology.
\end{abstract}

\section{Introduction}

Housing-and-communal services represent a dynamically developing branch, which essential directions of activity are:

- Maintenance and repair of the city roads;

- Gardening and improvement of the urban areas;

- Organization of water use and protection of water facilities ;

- Maintenance and repair of engineering structures;

- Organization of neutralization and processing of industrial and consumption waste;

- Operation of housing;

- Organization of self-government in the apartment houses;

- Social support of the population;

- Other measures.

Financing of these measures assumes serious burden for the municipal budget, and that makes the matter of the use of the scheme of public-and-private partnership and concession agreements (as a type of it) relevant.

*Corresponding authors: ella.o2011@yandex.ru 
International experience proves the success of the use of the public-and-private partnership mechanism for the creation of new facilities and for the maintenance of the existing city infrastructure and municipal economy as well. The problem of formation of The question of energy supply and energy conservation in modern construction industry not only occupies a major place in shaping technological solutions the construction of objects, but also acquires a social significance in the conditions of constant growth of expenses for all types of energy resources. The most important and urgent task of modern construction is the creation and implementation of new energy saving technologies, aimed at the subsequent effective operation of housing projects $[1,4]$. Energy efficiency is currently a key issue of the present stage of development of construction industry. But not only efficient energy saving technologies allow us to create buildings that meet the requirements of reducing operating costs, improving environmental performance of facilities that meet the new technological requirements. It is important when designing the residential buildings to save heat, electricity and other forms of energy, but you must use what you can get directly from the environment, i.e., renewable forms of energy.

To renewable types of energy include solar energy, which is actively used by many foreign countries because of its geographical situation in the zone of active collectanea throughout the year. Unfortunately, the Russian climate does not allow to apply such technology in a number of regions. In this region in the South of the country can use solar energy, successfully supplementing the natural sources of system energy consumption. In addition to solar energy to renewable species is also wind energy. It is also important to mention the possibility of use of the system of collection and purification of rainwater and wastewater as an efficient technology aimed at reducing water consumption $[2,10,13]$.

Efficient use of energy, above all, poses the problem of using less energy while maintaining the same level of energy supply to objects. Impact of energy on economic development of a society can be considered from the standpoint of extensive and intensive development. Extensive development of quantitative expansion of energy production and intensive development corresponds to an increase of efficiency of use of electricity.

\section{State-of-the-Art}

Despite the high level of effectiveness of these technologies, the main drawback is their relatively high cost. This is a major factor impeding the introduction of energy saving technologies in construction. All the above technologies require resources, not only financial but also productive. The construction company is not always able to execute the whole set of modern technologies. There are limitations on the resources and capabilities of the company.

Each alternative technology has a certain level of efficiency. As a rule, the efficiency can be detected within a certain period of use, when there is a reduction in operating costs $[11$, 14].

Suppose that the $i$-th company is considering for adoption to the execution of several types of high-tech solutions. For example, use of modern insulating materials, reduces the heat loss of the building to use a system of controlled ventilation, and to install solar panels on the roof of the building, as well as to create a wastewater treatment system for subsequent use for technical purposes. The company's resources are limited and allow for the simultaneous implementation of separate types of energy saving technologies (EST)

If the construction company has the ability to use multiple types of energy-saving technologies, it is also necessary to determine the optimal set ECT, providing the minimum level of costs for the design and construction of the subject innovation, as well as to solve the problem of choice of optimal technologies to obtain the maximum effect from implementation. It is advisable to choose the technology generating the greatest effect at minimum cost. The decision-making process can be formalized as a graphical structure. In 
this case, the problem of finding the optimal solutions solved in graph theory. Graphical modeling of the structure of relations allows to visualize and organize variants of the consistent use of energy saving technologies in construction companies [3].

Consider the task of organization of construction, which can be solved by methods of interpretation of the network using graph theory. Let there are n options for the use of energysaving technologies $\mathrm{m}$ construction companies (Fig. 1).

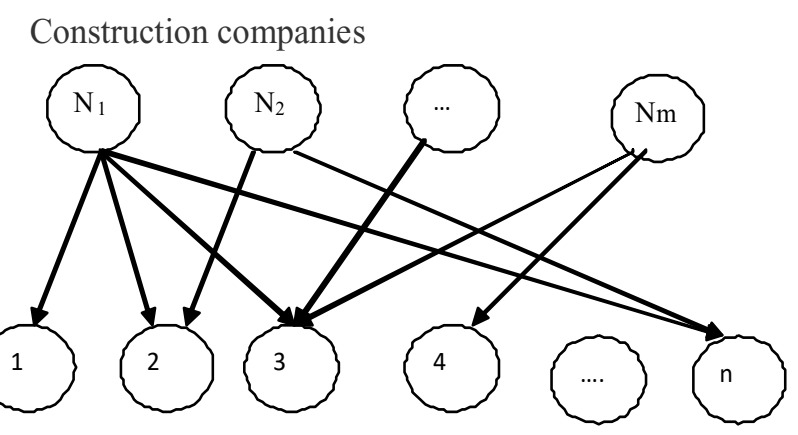

The types of EST

Fig. 1. A graph of decisions about the use of EST construction companies.

So, the company №1 considers it appropriate to use in the construction of object technology 1, 2, 3 and $\mathrm{n}$. The task requires determining the most rational solution from the point of view of minimization of costs for the introduction of EST, the efficiency of future operation, taking into account constraints on the resource capabilities of the company.

1 step. Suppose there are n projects of energy-saving technologies, each of which has a level of effectiveness $\mathrm{h}$. There is a limit on the capacity of construction companies for the implementation of all technology options

Resources construction companies are divided into:

- financial;

- material (availability of materials for production of individual units, components, etc.);

- technical (availability of required equipment for installation and subsequent maintenance of objects EST);

- labour (availability of skilled professionals for installation, Assembly, maintenance, equipment EST).

According to the resource capabilities of the construction company to build the matrix of binary relations (Table. 1). If the company has enough resources for implementation of energy efficient technologies in the table is the value 1 , if not -0 .

The determining factor in the decision may be financial resources, since the lack of technical base and qualified specialists for installation, mounting, commissioning, construction company may use subcontractors.

Table 1. Table of binary relations the ability of the company to use EST.

\begin{tabular}{|c|c|c|c|}
\hline \multirow{2}{*}{ The types of EST } & \multicolumn{3}{|c|}{ resources } \\
\cline { 2 - 4 } & financial & technical & labour \\
\hline 1 & 1 & 1 & 0 \\
\hline 2 & 0 & 1 & 1 \\
\hline 3 & 1 & 1 & 1 \\
\hline 4 & 1 & 0 & 1 \\
\hline 5 & 0 & 1 & 0 \\
\hline
\end{tabular}

The adjacency matrix of the graph has the form: 


$$
A_{N}=\left|\begin{array}{lll}
1 & 1 & 1 \\
0 & 1 & 0 \\
1 & 1 & 1 \\
1 & 0 & 1 \\
0 & 1 & 1
\end{array}\right|
$$

On the basis of the adjacency matrix revealed that the $\mathrm{N}$ company can take to implement EST No. 3, as in this case is the sufficiency of all resources of the company.

\section{Results}

Evaluation of the effectiveness of EST.

Each technology has increased efficiency. In General, the efficiency ratio for the ith technology can be represented in a general form

$$
h=\frac{Q_{i 0}-Q_{i 1}}{C_{i}} \rightarrow \max ,
$$

Where $\mathrm{Q}_{\mathrm{i} 0}$ is the consumption of energy to use $\mathrm{EST}_{\mathrm{i}}$; $\mathrm{Q}_{\mathrm{i} 1}$ - consumption of energy resources after the implementation of $\mathrm{EST}_{i} ; \mathrm{Ci}$ - the cost of implementation is $\mathrm{EST}_{\mathrm{i}}$

The effect of the use of modern technologies can only be assessed during the period of operation. As each type of resource has different units of measure (kWh, Gcal, etc.), then the effect should cause the indicators to a common equivalent, for example, to provide, in value terms, in relative terms, points, etc.

In value terms, the comparison of the characteristics in different periods of time present a performance indicator $\mathrm{H}$ :

$$
H=\frac{\sum_{i=1}^{t_{0}} \frac{c_{i 0} \cdot q_{i 0}}{(1+r)^{t_{0}}}-\sum_{i=t_{0}+1}^{t_{1}} \frac{c_{i 1} \cdot q_{i 1}}{(1+r)^{t_{1}-t_{0}}}}{C_{i}} \rightarrow \max
$$

$\mathrm{q}_{\mathrm{i} 0}$ - consumption of energy to use $\mathrm{EST}_{\mathrm{i}}$;

$\mathrm{q}_{\mathrm{i} 1}$ - consumption of energy resources after the implementation of $\mathrm{EST}_{\mathrm{i}}$;

$\mathrm{c}_{\mathrm{io}}$ - the cost of the consumption of units of the i-th type of energy source before the implementation of ECT;

$\mathrm{c}_{\mathrm{i} 1}$ - the cost of the consumption of units of the ith type of energy resource after implementation of EST;

$\mathrm{r}$ - the coefficient of indexation of cost of resource consumption;

$\mathrm{C}_{\mathrm{i}}$ - the cost of introducing energy-saving technologies of the $\mathrm{i}$-th species;

$\mathrm{n}$ - the period of operation to use energy-saving technologies;

$\mathrm{t}$ - total observation period; $\mathrm{t}-\mathrm{n}$ - period of commissioning of energy-saving technologies.

The cumulative effect of the use of energy-saving technologies will be different depending on the timing of the introduction of it into operation. The sooner will be introduced one or another form of EST, the faster the users of a residential facility receives the result from its implementation, which will be reflected in a significant reduction in operating costs for the provision of energy. 


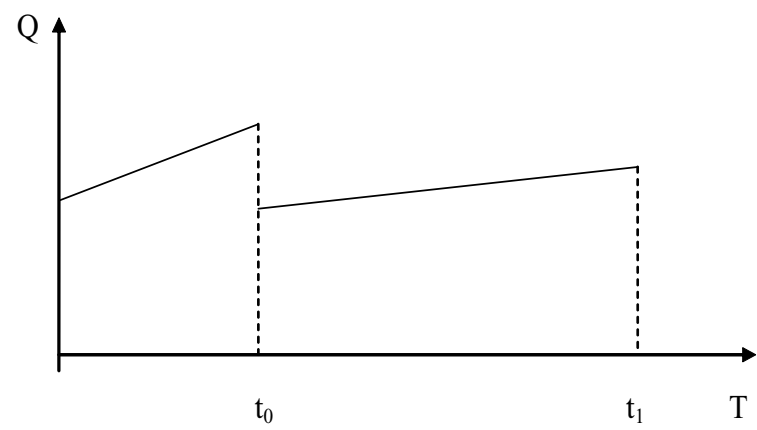

Fig. 2. Graph of the cumulative resource consumption for the operation period.

Indicator of the effectiveness of EST is calculated by the formula (2). Performance evaluation should take place not only considering the time factor during which occurs the operation of EST and determine the cumulative effect, but given the start time of operation. That is, in the earlier stages of commissioning EST the accumulation of a cumulative effect occurs faster with the same level of the used production resources (Fig. 3). Take the assumption that the construction company spends the same amount of resources on commissioning EST.

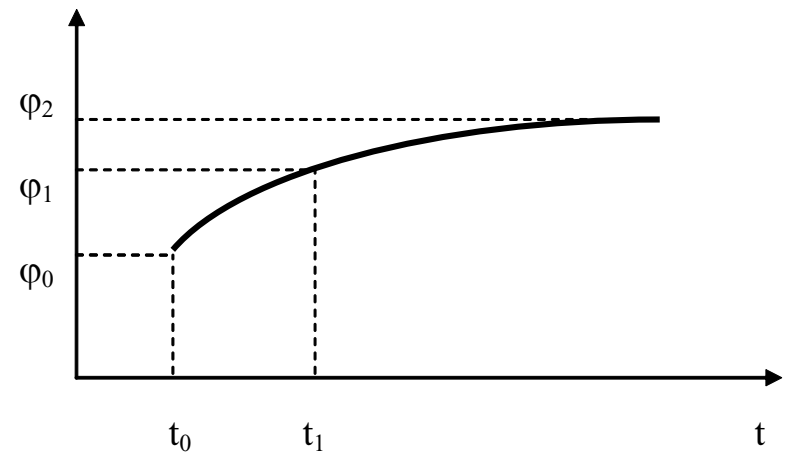

Fig. 3. The cumulative effect of EST in different stages of implementation.

Loss cumulative effect of deferred execution will be:

$$
\Delta F=\varphi_{1}-\varphi_{0}
$$

The index of potential losses will take the form:

$$
I_{P}=\frac{\Delta F}{C} \rightarrow \min
$$

Suppose the indexes of efficiency of energy-saving technologies $\mathrm{H}$ and the calculated index of potential loss of IP deferred the introduction of technology for the period $t$ :

Table 2. Table of calculated values ECT.

\begin{tabular}{|c|c|c|}
\hline The types of EST & H & Ip \\
\hline 1 & 20 & 0.145 \\
\hline 2 & 15 & 0.122 \\
\hline 3 & 27 & 0.017 \\
\hline 4 & 14 & 0,119 \\
\hline 5 & 22 & 0.067 \\
\hline
\end{tabular}


EST No. 3 is the minimum loss in the case of deferred execution. That is, technology No. 3 has high efficiency, but can be implemented in the next period. The loss in this case will be minimal [2].

Install limitations. Let the effect of $\mathrm{H}$ should be less than some value a, i.e. Ha; IP should not be less than some limit $b$, Ip $>b$. If the estimated values EST satisfy the conditions limit the effect of their use can be expressed in the form of binary relations.

Let $\mathrm{H}>18, \mathrm{Ip}>0,1$. Then given the constraints of the binary matrix will be the following.

Table 3. Table of binary relations the effectiveness of the use of ECT

\begin{tabular}{|c|c|c|}
\hline The types of EST & $\mathrm{H}$ & $\mathrm{Ip}$ \\
\hline 1 & 1 & 1 \\
\hline 2 & 0 & 1 \\
\hline 3 & 1 & 0 \\
\hline 4 & 0 & 1 \\
\hline 5 & 1 & 0 \\
\hline
\end{tabular}

The maximum effect and the inadmissibility of the later timing of the commissioning is ECT №1. EST №2 has a lower level of efficiency, it also, like №3, does not allow a later application. Construct the adjacency matrix of the computational efficiency of the ETS.

$$
A_{P}=\left|\begin{array}{ll}
1 & 1 \\
0 & 1 \\
1 & 0 \\
0 & 1 \\
1 & 0
\end{array}\right|
$$

Technology №1 conditions of effectiveness. But it is necessary to designate priorities. The index $H$ evaluates the effectiveness, in terms of energy saving. The $I p$ index evaluates the period of commissioning ECT. I $=0$ shows that under the condition of inability to purchase necessary equipment or lack of appropriate resources for the specified type of ECT without significant losses can be deferred for implementation in the period $\Delta \Delta t=t_{1}$ $\mathrm{t}_{0}$. Conversely, if $I p=1$, this means that to postpone the implementation of the implementation of EST is inappropriate, it will cause a substantial loss of profits.

Therefore, on the basis of calculations of the construction company should take to implement in the first place technology No. 1, as it has the proper level of efficiency and does not allow for the postponement of the implementation [3].

This allows us to construct a digraph with consistent project execution. The digraph is based on the priority of the efficiency of $\mathrm{H}$. Subsequent paths are also focused on this figure, but of the possible options first select ECT with the highest value $I p$. Happens ranking the nodes in descending order of $I p$.

For the studied construction companies $N$ the digraph will look in the form of oriented chains (Fig. 4). The vertices of the graph represent the types of ECT, preserving the sequence of execution according to the principle of decreasing indicator Ip, where root is the technology №1, meet on the grounds of efficiency and the conditions for priority of execution.

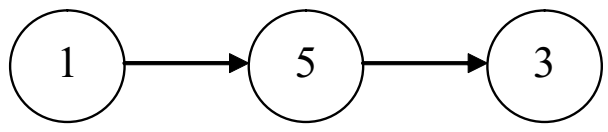

Fig. 4. Oriented chain ECT with different implementation dates. 


\section{Discussion}

For Russia as a country with a relatively cold climate in many regions an important issue is the use of modern resource-saving technologies aimed at reducing heat loss of buildings. Heat retention is largely dependent on the use of building envelopes and associated design solutions. Currently, various types of materials and structures can significantly change the heat loss of the building. For example, the use of energy saving modular ventilated facade system "Marmorok", which has more than 15 years is tested as in the construction of new buildings and renovation of existing ones.

Facade system that has devices for ventilation, was developed by Swiss scientists back in the 60 -ies of the last century. This facade system used in the construction and operation of buildings in the EU, and in addition, and in Japan. It works successfully in the most diverse climatic conditions. In addition, the use of the system in Japan have confirmed its high seismic resistance [1].

This system is manufactured in our country, and have the certificate confirming its compliance with the quality standard EN ISO 12944-2. Currently, the system has been successfully used in the construction of buildings almost the entire territory of our country, including in Voronezh. Such a high applicability of the system "Marmorok" ensure its high performance: the function of "breathing wall", which provides ventilation of the facades, the function of aesthetics, providing a beautiful appearance of the facade, and the most important thing in our difficult climatic conditions - the function of heat conservation. All of these features are complemented by the efficiency not only during operation of the system "Marmorok", as well as in the production of construction works, since the use of the system ensures high productivity.

In addition to the system "Marmorok" there are many other heat-saving technologies. The most common technologies include: mineral insulation, polystyrene concrete, foam, and heat-saving design of doors and Windows, which is especially important in the organization of the system of heat conservation.

The amount of heat loss of a building can be significantly reduced through the use of glazing with electrical heating.

The use of glazing with electrical heating involves both external (for example, for transparent roofs to prevent the accumulation of snow and ice), and internal (to create comfort in the room, heating conservatories, etc.) installation. Designed glazing with electrical heating of one or two glasses.

The following energy-saving technologies - heat aluminum profiles. The attractiveness of aluminum for the construction lies in the fact that it is a simple material to handle, allowing to implement new ideas in design, but its essential disadvantage is the high conductivity. To compensate for this disadvantage of the use of aluminum structures enabled the so-called "warm" system, consisting of two aluminum profiles separated by a polyamide layer, called a thermal bridge or thermal break. The advantages of polyamide not only low thermal conductivity but also in strength, aging resistance, moreover, the linear expansion coefficient of the polyamide corresponds approximately to the same figure for aluminium. This ensures that the adjoint operation of all layers of the design and prevents the accumulation of residual strain over time. This fact allows to ensure high accuracy of the sizes of the structure and ensure the possibility of wide variation of configurations to perfectly pair with the aluminium part of the profile.

The main disadvantage of heat of aluminium profiles is their high price, therefore, the manufacture of complex shaped structures not available to every manufacturer.

Recently became aware of the existence of low-emissivity glasses. For the manufacture of such glasses need to apply a nano-coating of metal on a piece of glass. This nanoprovides dual action: in addition, heat stored in the building, and solar radiation easily penetrates to 
the premises, lighting and heating it. Nanocoatings are divided into two types: i-glass with soft coating and k-glass with hard. Their differences manifest themselves in the methods of manufacture and qualitative characteristics of ultra-thin coatings of glass [1].

Of course, this additional pressure on the glass as the application of nano-coating that makes the higher its cost: 1-chamber double-glazed window is about 1.5 times more expensive than the same without nanocoating, and 2-chamber will cost twice the price of the glass without causing ultrafunkula low emissivity coating. However, the energy efficiency of these glass much higher, which makes their use profitable and beneficial.

The following form is very effective heat technology - frame fiberglass composite. The climatic conditions of large areas of Russia involve significant temperature variations throughout the year: in winter, severe frosts, and in summer the intense heat. Due to the impact of Windows on a significant temperature variations be gaps between the frame and glass.

Because they are made of materials having different linear expansion - hence, their dimensions change under the effect of temperature variation is different. This implies that there is an invisible strain, which greatly reduces the energy efficiency of the glazing due to the formation of gaps and, consequently, penetration of outdoor air into the room. To address this significant drawback, the proposed use of frames, which are made of fiberglass.

A distinctive feature of the composite manufactured using polyester resins and glass fibers, is the high degree of similarity of linear expansion with the glass. This material has excellent performance qualities such as durability, high strength, low thermal conductivity, easy painting, high fire resistance, etc. The real life of window frame are made of a composite is twenty-five years. Theoretical durability of fiberglass is fifty years [5, 8,15].

The strength of such frames is comparable with the strength of steel frames. Composite frames can withstand pressure of up to $1180 \mathrm{MPa}$, and the Flexural strength of this material up to $1210 \mathrm{MPa}$. In addition, unlike metal, fiberglass is not oxidized and do not corrode. Due to the high strength fiberglass little prone to chipping and scratches, which gives it an attractive appearance.

Currently use another method for reducing infrared heat losses. Is the use of a heat reflective film coating. They consist of 2 layers of material between which is stretched a metal foil, and its thickness is very small. The main advantages of this film are its chemical inertness, and high strength, which allows it to withstand the pressure of the order of twentyfive atmospheres. In addition, the film easy to clean (without the use of abrasive materials). To protect against mechanical damage it is covered with special composition.

The use of films of this kind promotes the absorption of almost the entire short-wave spectrum of solar radiation. In addition, absorbed a significant portion of the visible solar radiation, thus reducing the "blinding" effect of radiation in some cases up to $88 \%$. And the reflection of infrared radiation is in the range of $70 \%$. Such quality films allow to reduce the cost of space heating in the cold season. In the heat in the bedrooms remain cool, and, as a consequence, reduces the need for air-conditioning of these premises.

Another interesting quality of the films is "mirror effect", that is, the inside of the premises not visible from the street, while inside the room the view is fully preserved. In addition, using the tape, you can avoid the aggressive effects of sunlight on the decoration and furnishings that will keep their original appearance for a much longer period of time.

In case of emergency, the film allows you to make glass safer, it increases the resistance to flame in case of fire; if the glass is broken, it stays on tape, not scatters splinters, injuring occupants in the room of people. In addition, it increases the strength of the window. For example, glass coated with a film A3 (protection class - vandal proof) can not be broken, if from the height of $10 \mathrm{~m}$ the object will fall weighing about $4 \mathrm{~kg}$. the Cost of installation is quite high, but the effect of its application is obvious. 


\section{Conclusion}

Thus, on the basis of the construction of adjacency matrices organization of construction production is planned with the use of energy-saving technology identifies the optimal combination possibilities i-the construction company and the effectiveness to the execution of the technology.

\section{References}

1. E.Y. Okolelova, R.D. Zilberov, Economics and management control systems 1.1(11), 126-130 (2014)

2. N.I. Trukhina, Scientific aspects of control of real estate in housing sphere. Monograph (Voronezh state University, Voronezh, 2006)

3. E.Y. Okolelova, R.D. Zilberov, H.Ch. Toan, Economics and management control systems 1.1(11), 156-161 (2014)

4. N.I. Trukhina, V.N. Barinov, FES: Finance. Economy. Strategy 2, 42-46 (2012)

5. O.V. Kornicka, E.Y. Okolelova, N.I. Trukhina, Management of economic systems: electronic scientific journal 12(60), 93 (2013)

6. S.G. Sheina, R.D. Zilberov, Economics and management of control systems 2(12), 110116 (2014)

7. A.P. Dzyuba, Energy, 3 (2017)

8. A.S. Vilkova, , K.A. Petulko, Young scientist 8, 1268-1271 (2016)

9. N.I. Trukhina, I.I. Chernyshikhina, Vestnik MGSU 9, 227-233 (2012)

10. N.I. Trukhina, E.A. Pogrebennaya, Labour and social relations 3, 57-62 (2010)

11. E.Y. Okolelova, N.I. Trukhina, Construction of high-rise buildings: performance evaluation of projects under conditions of risk. Monograph (VGASU, Voronezh, 2016)

12. E. Chibisova, T. Meshcheryakova, Science Krasnoyarya 6(2-2), 146-148 (2017) 